\title{
REKAYASA ALAT PENYARING LIMBAH CAIR MODEL SCREW CONVEYOR (STUDI KASUS: LABORATORIUM PENGEMBANGAN PENYAMAKAN DAN PENGOLAHAN LIMBAH KULIT BALAI BESAR KULIT, KARET, DAN PLASTIK)
}

\section{DESIGN OF SCREW CONVEYOR MODELS FOR WASTE WATER FILTER EQUIPMENT (CASE STUDY: LABORATORY FOR DEVELOPMENT OF TANNING AND WASTE WATER TREATMENT, CENTER FOR LEATHER, RUBBER, AND PLASTIC)}

\author{
Tri Rahayu Setyo Utami*, M. Rahna Nurhandaru, Teguh Martianto \\ Balai Besar Kulit, Karet, dan Plastik Yogyakarta \\ *E-mail: setyoutami79@gmail.com
}

Diterima: 5 Oktober 2013 Direvisi: 20 Desember 2013 Disetujui: 24 Desember 2013

\begin{abstract}
Tanning industry produces large amounts of wastewater which contains much solid particles. If left unchecked, the solids can block the pipe and damage equipments of wastewater treatment plant.Hence, the suspended fine solid must be separated from the wastewater. This engineering activity has generated screw conveyor models for wastewater filter. The specifications of the filter are screw diameter $300 \mathrm{~mm}$, pitch distance $150 \mathrm{~mm}$, shaft diameter $25.4 \mathrm{~mm}$, screw length 1200 $\mathrm{mm}$, tilt angle $25^{\circ}$, and screw actual capacity 42.237,99 kg/hour. Propulsion system comprising an inverter, 3 phase, $1 \mathrm{hp}$ electric motors; and gear box. The advantages of this equipment are the effectiveness of filtering up to $90 \%$, easy operation and maintenance, and the filtered solid is in half dried conditions, so it is easy to store and transport.
\end{abstract}

Keywords: screening, screw conveyor, wastewater

\begin{abstract}
ABSTRAK
Industri penyamakan kulit menghasilkan limbah cair dalam jumlah besar dan merupakan masalah yang serius bagi lingkungan. Limbah cair ini banyak mengandung partikel atau benda padat. Jika dibiarkan, padatan dalam limbah cair ini akan mengendap yang berakibat tersumbatnya saluran air dan gangguan mesin/peralatan yang dipasang di IPAL. Perlu dilakukan penyaringan untuk mengambil zat padat halus yang tersuspensi di limbah cair. Kegiatan perekayasaan ini telah menghasilkan alat penyaring limbah cair model screw conveyor. Alat yang dihasilkan mempunyai spesifikasi diameter screw $300 \mathrm{~mm}$, jarak pitch $150 \mathrm{~mm}$, diameter poros 25,4 mm, panjang screw $1200 \mathrm{~mm}$, sudut kemiringan $25^{\circ}$, dan kapasitas aktual screw 42.237,99 kg/jam. Sistem penggeraknya terdiri atas: inverter; motor listrik 3 fase, $1 \mathrm{hp}$; dan gear box. Kelebihan alat ini adalah efektivitas penyaringannya mencapai $90 \%$, mudah pengoperasian dan perawatan, dan padatan yang tersaring dalam kondisi setengah kering sehingga memudahkan dalam penyimpanan dan pengangkutan.
\end{abstract}

Kata kunci: penyaring, screw conveyor, limbah cair

\section{PENDAHULUAN}

Proses penyamakan kulit adalah proses pengolahan kulit binatang dengan menggunakan berbagai bahan kimia pembantu proses. Proses penyamakan kulit menggunakan air dalam jumlah besar yaitu $15-20 \mathrm{~m}^{3} /$ ton kulit mentah. Proses penyamakan kulit menghasilkan sejumlah besar limbah dalam bentuk lumpur, cair dan padatan. Limbah proses penyamakan kulit ditandai dengan nilai $\mathrm{COD}, \mathrm{BOD}$ dan 
konduktivitas yang tinggi (Krishanamoorthi et al., 2009).

Limbah cair yang dihasilkan dari proses penyamakan kulit berwarna sangat keruh dan berbau busuk. Limbah cair penyamakan kulit mengandung komponen utama yaitu sulfida, kromium, senyawa organik yang mudah menguap, padatan dalam jumlah besar, padatan tersuspensi seperti bulu hewan dan potonganpotongan kulit (Midha and Dey, 2008). Padatan tersuspensi jika dibiarkan suatu saat akan mengendap yang akibatnya dapat menyebabkan penyumbatan saluran air dan gangguan mesin peralatan yang dipasang di Instalasi Pengolahan Air Limbah (IPAL) sehingga dalam proses pengolahan limbah cair di IPAL langkah pertama yang dilakukan adalah melakukan penyaringan.

Padatan berukuran besar dipisahkan dari cairan dengan saringan kasar yang berukuran lubang 2-10 $\mathrm{mm}$. Padatan berukuran kecil dipisahkan dengan saringan halus berukuran lubang 0,2-2 $\mathrm{mm}$ (Libhaber and OrozcoJaramillo, 2012). Saringan halus yang banyak digunakan di industri penyamakan kulit adalah jenis mechanical brushing screen.

Saringan jenis mechanical brushing screen kurang efektif karena jika sikat yang digunakan terlalu rapat maka cairan banyak yang ikut terambil dan jika sikat yang digunakan kurang rapat maka proses penyaringan tidak maksimal. Saat ini industri penyamakan kulit kesulitan mendapatkan penyaring limbah cair yang tepat, sehingga perlu dicari sebuah model alat penyaring limbah cair yang optimal proses penyaringannya dan mampu mengangkut/ mengambil padatan tersaring yang halus atau seperti bubur. Model yang dipilih adalah model screw conveyor.

Screw conveyor banyak digunakan di industri pertanian dan pengolahan untuk mengangkut atau mengangkat material dalam waktu yang lebih singkat (Owen and Cleary, 2009; Zareiforoush et al., 2010). Screw conveyor terdiri atas screw (ulir) yang berputar, celah sebagai pintu masuk dan keluar material, dan peralatan penggerak. Alat penggerak terdiri atas motor dan reducer (penurun kecepatan), coupling dan dudukan ( $\mathrm{Li}$ and Liu, 2013). Screw conveyor merupakan alat angkut material yang berbentuk butiran kecil, bubuk, dan cairan dalam berbagai bidang industri. Screw conveyor mempunyai poros spiral yang berputar dalam pipa. Screw conveyor mengangkut material dengan memanfaatkan gerakan putaran poros screw (Bolat and Bogoclu, 2012).

Huda (2010) memanfaatkan mekanisme screw conveyor dalam perancangan sludge dewatering unit. Sludge dewatering unit pada penelitian Huda (2010) digunakan sebagai pemisah lumpur padat (sludge) pada proses pencernaan anaerobik pada pengolahan limbah buah untuk biogas sebagai pupuk organik. Desain sludge dewatering unit dibuat dengan menggabungkan pompa Archimedes di zona pompa dan sekrup pengepres di zona dewatering.

Pada kegiatan perekayasaan ini mekanisme screw conveyor digunakan sebagai alat penyaring limbah cair industri penyamakan kulit. Model screw conveyor dipilih karena model ini yang paling tepat untuk mengangkut bahan padat berbentuk halus, cara kerja yang sederhana sehingga mudah pengoperasian, dan mudah dalam perawatan. Prinsip kerja penyaring limbah model screw conveyor memanfaatkan gerakan putar yang dihasilkan screw untuk mendorong keluar padatan yang terbentuk dari hasil penyaringan. Perbedaan perekayasaan ini dengan penelitian Huda (2010) adalah material yang diangkut dan kombinasi dengan pompa archimedes. Material yang diangkut Huda (2010) berupa limbah buah yang berbentuk padat.

\section{BAHAN DAN METODE}

\section{Bahan Penelitian}

Bahan yang digunakan pada kegiatan rekayasa ini adalah motor listrik $1 \mathrm{HP}, 3$ phase, $1400 \mathrm{rpm}$; inverter, 200-230 V, 1 phase; gearbox, 1:50; as stainless steel 304; laker; plat baja stainless steel 304; siku stainless steel 304; perforated stainless steel 304; dan elektroda las stainless steel.

\section{Peralatan Penelitian}

Alat yang digunakan pada kegiatan rekayasa ini meliputi gergaji, mesin las, kompresor, mesin bor, dan peralatan bengkel lainnya.

\section{Metode Penelitian}

Penghitungan untuk menentukan dimensi 
alat yang akan dibuat menggunakan persamaan (1) berikut.

$$
\mathrm{Q}_{\text {teori }}=2 \times \mathrm{Q}_{\text {act }}
$$

$\mathrm{Q}_{\text {teori }}$ adalah kapasitas teori $(\mathrm{kg} / \mathrm{j})$ dan $\mathrm{Q}_{\text {act }}$ adalah kapasitas aktual $(\mathrm{kg} / \mathrm{j})$.

Hubungan kapasitas screw conveyor dengan dimensi dan putaran screw dihitung dengan persamaan (2) berikut.

$\mathrm{Q}_{\text {teori }}=\frac{3,14 \times(\mathrm{D}-\mathrm{d})^{2} \times \mathrm{s} \times \mathrm{n} \times \rho \times \mathrm{i} \times 60}{4}$

D adalah diameter screw conveyor (m), d adalah diameter poros screw (m), s adalah jarak pitch (m), $\mathrm{n}$ adalah putaran screw (rpm), $\rho$ adalah densitas material yang diangkut, dan i adalah faktor sudut kemiringan screw.

Kebutuhan motor penggerak $(\mathrm{P})$ ditentukan dengan persamaan (3) berikut.

$\mathrm{P}=\frac{\mathrm{Q}_{\text {teori }} \times \mathrm{L} \times \mathrm{K}}{407}$

$\mathrm{P}$ adalah daya motor $(\mathrm{kW}), \mathrm{L}$ adalah panjang conveyor, dan $\mathrm{K}$ adalah koefisien friksi.

Kecepatan alir maksimum untuk screw penyaring limbah dihitung dengan persamaan (4).

$\mathrm{v}=\frac{\mathrm{t} \times \mathrm{n}_{\mathrm{m}}}{60}$

v adalah kecepatan alir maksimum, t adalah jarak pitch, dan $\mathrm{n}_{\mathrm{m}}$ adalah putaran maksimal alat.

Diameter screw conveyor (D) ditetapkan $0,3 \mathrm{~m}$, diameter poros (d) $0,0254 \mathrm{~m}$, berat jenis ( $\rho)$ padatan $1600 \mathrm{~kg} / \mathrm{m}^{3}$, jarak pitch (s) $0,15 \mathrm{~m}$, dan kecepatan putaran (n) 4 rpm. Dilakukan variasi sudut kemiringan srew conveyor $25^{\circ}$ dan $40^{\circ}$.

Setelah diketahui ukuran alat yang akan dibuat, selanjutnya dibuat desain alat penyaring limbah cair model screw conveyor lengkap dengan ukuran menggunakan program autoCAD. Langkah berikutnya adalah pembuatan alat penyaring limbah cair model screw conveyor menggunakan peralatan seperti gergaji, mesin las, kompresor dan peralatan bengkel lainnya. Screw conveyor yang diperoleh diuji coba untuk mengetahui unjuk kerja mesin/alat. Dari uji coba diharapkan dapat diketahui kekurangan mesin/ alat sehingga jika diperlukan akan dilakukan perbaikan. Alat ini dirancang untuk digunakan di IPAL Laboratorium Pengembangan Penyamakan Dan Pengolahan Limbah Kulit Balai Besar Kulit, Karet Dan Plastik (LP3LKBBKKP) Yogyakarta.

\section{HASIL DAN PEMBAHASAN \\ Desain Alat}

IPAL LP3LK-BBKKP mempunyai kapasitas aktual $\left(Q_{\text {act }}\right)$ sebesar $30 \mathrm{~m}^{3} /$ hari dimana 1 hari beroperasi selama 8 jam. Hal ini berarti $Q_{\text {act }}$ sebesar $3,75 \mathrm{~m}^{3} / \mathrm{jam}$. Berdasarkan persamaan (1) didapatkan $Q_{\text {teori }}$ sebesar 7,50 $\mathrm{m}^{3} / \mathrm{j}$. Jika dimasukkan berat jenis padatan yang tersaring ( $\rho)$ yaitu $1600 \mathrm{~kg} / \mathrm{m}^{3}$, maka akan didapatkan $\mathrm{Q}_{\text {teori }}$ sebesar $12000 \mathrm{~kg} / \mathrm{j}$.

Limbah cair industri penyamakan kulit bervariasi dalam volume dan konsentrasi karena untuk proses penyamakan terus-menerus dan debit yang bervariasi. Sulfida adalah salah satu komponen utama dari limbah penyamakan kulit. Sulfida menyebabkan iritasi, bau busuk dan pada konsentrasi di atas $10 \mathrm{ppm}$ terjadi pemaparan toksikologi. Hal ini sangat berbahaya bagi manusia. Sulfida juga mempunyai sifat korosif yang menyebabkan kerusakan dinding beton reaktor, sistem saluran pembuangan dan pipa baja (Midha and Dey, 2008). Oleh karena itu, dalam rekayasa alat penyaring limbah cair industri penyamakan kulit dibutuhkan material logam yang tahan korosi. Salah satu material yang mempunyai sifat tahan korosi yang bagus adalah stainless steel.

Stainless steel merupakan salah satu logam paduan dengan logam induk besi $(\mathrm{Fe})$ yang mengandung minimum $11 \mathrm{wt} \% \mathrm{Cr}$. Stainless steel selain mengandung unsur $\mathrm{Fe}$ dan $\mathrm{Cr}$ juga diperkuat dengan unsur lain seperti Molibden (Mo), Nikel (Ni) dan Mangan (Ma) yang bertujuan untuk meningkatkan propertisnya (Lo et al, 2009). Stainless steel umumnya digunakan pada kondisi yang memerlukan ketahanan korosi yang sangat bagus dan mempunyai kekuatan mekanik yang bagus (Sudjatmoko et al., 2013). Hasil survei bahan mendapatkan kesimpulan untuk membuat penyaring limbah model screw conveyor dipilih bahan dari jenis stainless steel 304 dengan pertimbangan stainless steel 304 
mempunyai kandungan Nikel (8-12) \%. Hal ini membuat stainless steel 304 mempunyai ketahanan terhadap asam dan basa cukup bagus. Stainless steel 304 juga mempunyai sifat mekanik yang bagus untuk konstruksi.

Selanjutnya dilakukan penghitungan kebutuhan motor penggerak. Kebutuhan motor penggerak dihitung menggunakan persamaan (3) dengan panjang conveyor (L) $1200 \mathrm{~mm}$. Berdasarkan perhitungan didapatkan hasil untuk rekayasa alat penyaring limbah cair dibutuhkan daya minimal 0,180 kW setara dengan 0,241 HP. Dalam kegiatan rekayasa ini, dipilih penggerak motor listrik 3 phase, 1 HP karena motor dengan daya 1 HP daya aktual yang keluar dari motor adalah $\pm 50 \%$ dari daya yang tertera di name plate motor.

Tahapan pembuatan desain alat menghasilkan penyaring limbah cair yang akan dibuat mempunyai model seperti screw conveyor tetapi bagian bawah casing diganti dengan perforated stainless steel 304 dengan ukuran diameter lubang $2 \mathrm{~mm}$. Penyaring limbah yang akan dibuat mempunyai diameter screw (d) $300 \mathrm{~mm}$, jarak pitch (s) $150 \mathrm{~mm}$, diameter poros $25,4 \mathrm{~mm}$, panjang screw $1200 \mathrm{~mm}$, dan motor penggerak 3 phase, 1 HP.

\section{Rekayasa Alat}

Pembuatan screw conveyor dilakukan dengan pembuatan impeler dari lembaran stainless steel 304 dengan tebal $2 \mathrm{~mm}$ dan selanjutnya dilas dengan poros (shaft) screw seperti terlihat pada Gambar 1(a). House conveyor terbuat dari perforated stainless steel. Antara house dan screw conveyor dibuat presisi sehingga padatan yang tertinggal di dalamnya dapat terdorong keluar dari house conveyor. House conveyor terbuat dari perforated stainless steel 304 dengan diameter lubang 1,5 mm. Frame atau kerangka dudukan terbuat dari stainless siku 201. House conveyor dipasang pada frame, selanjutnya screw dipasang pada house seperti ditunjukkan Gambar 1(b). Langkah terakhir adalah pemasangan gear box, motor listrik, inverter dan pemasangan talang dan tutup screw seperti ditunjukkan Gambar 1(c) dan Gambar 1(d).
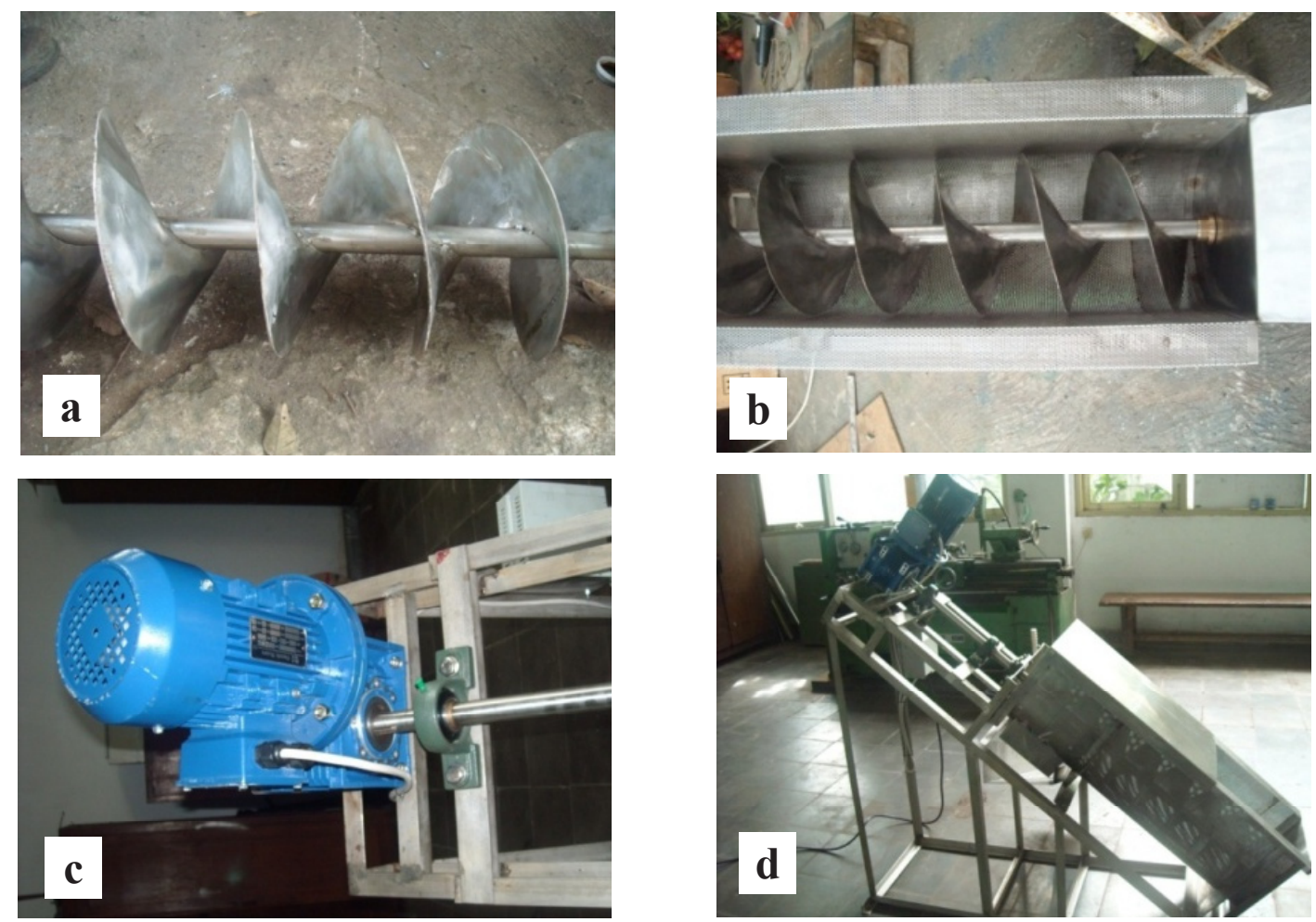

Gambar 1. Alat penyaring limbah sistem rotari model screw conveyor: (a) Poros screw conveyor, (b) Screw conveyor yang dipasangkan house conveyor, (c) Sistem transmisi, (d) pemasangan talang dan tutup screw 


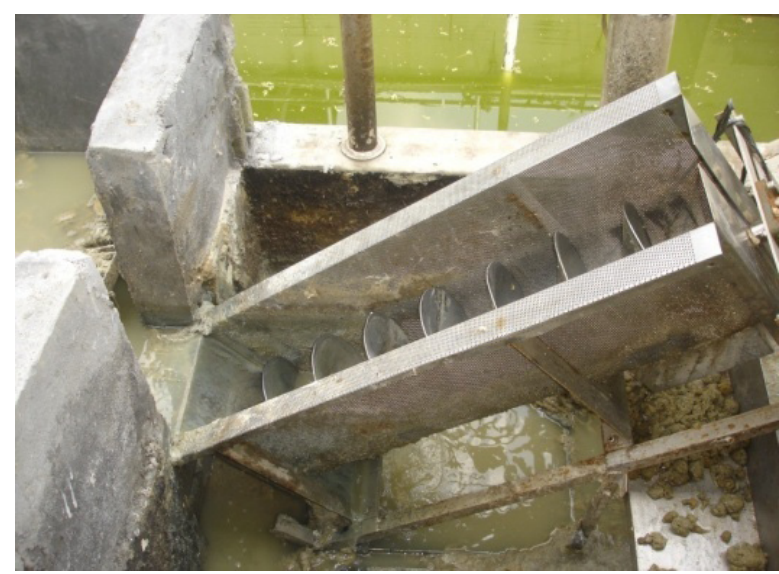

Gambar 2. Instalasi dan uji coba alat

\section{Uji Coba Alat}

Alat yang diperoleh diuji coba untuk mengetahui kinerja alat. Instalasi alat dilakukan di IPAL LP3LK BBKKP yaitu setelah bak pertama seperti ditunjukkan Gambar 2. Hasil uji coba alat menunjukkan bahwa semua elemen mesin bekerja optimal. Hasil uji coba alat dengan sudut kemiringan screw conveyor $40^{\circ}$ padatan yang terbentuk hasil penyaringan tidak terdorong menuju pintu keluar sehingga proses penyaringan tidak optimal. Hasil uji coba alat dengan sudut kemiringan screw conveyor $25^{\circ}$ padatan yang terbentuk hasil penyaringan mampu didorong menuju pintu keluar. Sehingga dapat disimpulkan sudut kemiringan yang optimal untuk alat penyaring limbah cair ini $25^{\circ}$. Pengaruh kemiringan screw conveyor terhadap kapasitas juga diteliti oleh Asli-Ardeh dan Mohsenimanesh (2012) dimana semakin besar sudut kemiringan screw conveyor maka kapasitasnya semakin kecil. Hal ini diduga karena tergelincirnya sebagian padatan sehingga kembali ke bawah. Berdasarkan persamaan (2) untuk sudut kemiringan $25^{\circ}$ didapatkan $\mathrm{Q}_{\text {teori }}$ sebesar 85.237,99 kg/jam.

Motor listrik, gear box dan inverter diletakkan dalam kondisi terbuka, tanpa pelindung sehingga rawan jika kondisi hujan. Untuk mengatasi hal ini motor listrik dan gear box diberi penutup sementara inverter diletakkan di dalam panel listrik dan di dalam ruangan yang terlindung dari hujan.

IPAL LP3LK adalah IPAL tanpa bak penampung, jadi ketika debit aliran limbah dalam kondisi maksimal maka air limbah sebagian meluap ke samping tidak seluruhnya masuk ke screw penyaring. Untuk mengatasi hal ini dibuat dinding samping sehingga tidak ada celah antara bak limbah dengan permukaan screw. Kecepatan alir maksimum untuk screw penyaring limbah untuk jarak pith $0,15 \mathrm{~m}$ dan putaran maksimal alat $29 \mathrm{rpm}$ diperoleh dari persamaan (4) sebesar $0,07 \mathrm{~m} / \mathrm{s}$.

\section{KESIMPULAN DAN SARAN Kesimpulan}

Telah dihasilkan alat penyaring limbah cair sistem rotari dengan model screw conveyor dengan spesifikasi sebagai berikut: diameter screw, d: $300 \mathrm{~mm}$, jarak pitch, s: $150 \mathrm{~mm}$, diameter poros: $25,4 \mathrm{~mm}$, panjang screw: 1200 mm, sudut kemiringan: $25^{\circ}$, kapasitas teori: $85.237,99 \mathrm{~kg} / \mathrm{jam}$, kapasitas aktual screw: $42.618,99 \mathrm{~kg} / \mathrm{jam}$, sistem penggeraknya terdiri atas: inverter, motor listrik 3 phase, $1 \mathrm{HP}$ dan gear box.

\section{Saran}

Kekurangan alat penyaring limbah model screw conveyor yang perlu diperbaiki adalah posisi motor listrik, gear box dan inverter dalam kondisi terbuka tanpa pelindung membuatnya rawan jika dalam kondisi hujan; perlu dibuat tutup samping agar limbah tidak meluap.

\section{UCAPAN TERIMA KASIH}

Terima kasih disampaikan kepada Kepala Balai Besar Kulit, Karet dan Plastik yang telah memberikan kesempatan kepada penulis untuk melakukan kegiatan perekayasaan ini. Terima kasih pula penulis sampaikan kepada semua pihak yang telah membantu sehingga kegiatan perekayasaan ini dapat berjalan lancar.

\section{DAFTAR PUSTAKA}

Asli-Ardeh, E. A. and Mohsenimanesh, A., 2012. Determination of effective factors on power requirement and conveying capacity of a screw conveyor under three paddy grain varieties, The Scientific World Journal, 2012.

Bolat, B. and Bogoclu, M. E., 2012. Increasing of screw conveyor capacity, Journal of Trends in The Development of Machinery and Associated Technology, 16(1): 207- 
210.

Huda, Y. F., 2010. Rancang bangun sludge dewatering unit dengan mekanisme screw conveyor: Studi eksperimen pengolahan sludge sampah buah sebagai bahan baku pupuk organik di Pasar Buah Gamping Sleman, Tesis, Universitas Gadjah Mada.

Krishanamoorthi, S., Sivakumar, V., Saravanan, K., and Prabhu, T. S., 2009. Treatment and reuse of tannery waste water by embedded system, Modern Applied Science, 3(1): 129-134.

Li, H. and Liu, W., 2013. The exprimental research of screw conveyor feeding system, Applied Mechanics and Materials, 251: 101-103.

Libhaber, M. and Orozco-Jaramillo, Á., 2012. Sustainable treatment and reuse of municipal wastewater: For decision makers and practicing engineers, Iwa publishing, London.

Lo, K. H., Shek, C. H., and Lai, J. K. L., 2009. Recent development in stainless steel, Materials Science and Engineering: $R$ : Reports, 65(4): 39-104.
Midha, V. and Dey, A., 2008. Biological treatment of tannery wastewater for sulfide removal, International Journal of Chemical Sciences, 6(2): 472-486.

Owen, P. J. and Cleary, P. W., 2009. Screw conveyor performance comparison od discrete element modelling with laboratory experiments, Seventh International Conference on CFD in The Minerals and Process Industries, CSIRO, Melbourne.

Sudjatmoko, Susita, R., M., L., Wirdoadi, dan Siswanto, B., 2013. Peningkatan ketahanan korosi AISI 316L stainless steel menggunakan implantansi ion nitrogen, Jurnal IPTEK Nuklir Ganendra, 16(2): 6775.

Zareiforoush, H., Komarizadeh, M. H., and Alizadeh, M. R., 2010. Performance evaluation of a $15.5 \mathrm{~cm}$ screw conveyor during handling process of rough rice (Oriza Sativa L.) grains, Nature and Science, 8(6): 66-74. 